Leading Article

\title{
Immunopathology of Behçet's disease
}

\author{
R.J. Powell and S. Dunstan
}

Immunology Department, University Hospital, Queen's Medical Centre, Nottingham NG7 2UH, UK

Behçet's disease (BD) is best considered as a systemic vasculitis in which recurrent orogenital ulceration is a prominent feature. In 1937 Hulusi Behçet described the syndrome that bears his name ${ }^{1}$ but the term 'Behçet's disease' is now used in preference to 'Behçet's syndrome'. Behçet, himself, recognized the problems related to its diagnosis for which there remains no diagnostic test. BD is rare in Britain but it affects up to 1:1000 of the population of Japan. The increased incidence in Far Eastern countries ${ }^{2}$ and in the eastern Mediterranean, ${ }^{3}$ and an association with HLA B5 $5^{4,5}$ suggest that environmental and genetic factors are important influences in the aetiology of BD.

Until recently, 5 sets of diagnostic clinical criteria for BD were variously used around the world, each with its own emphasis on symptoms and signs pertaining to a particular geographical region. In 1990 new criteria for the diagnosis of BD, proposed by an international study group, were published ${ }^{6}$ and these should facilitate comparisons between studies and hopefully foster collaborative work.

Criteria:-

Recurrent oral ulceration

Plus 2 out of:-

Recurrent genital ulceration

Eye lesions

Skin lesions minor aphthous, major aphthous, or herpetiform ulceration which has recurred $>3$ times in a one year period.

aphthous ulceration or scarring. Anterior/posterior uveitis, or cells in vitreous on slit lamp examination; or retinal vasculitis observed by ophthalmologist.

erythema nodosum, pseudo-folliculitis, or papulopustular lesions; or acneiform nodules observed by physician in postadolescent patients not on corticosteroid treatment.

Positive pathergy test Read by physician at 24-48 h.

(All findings applicable only in absence of other clinical explanations).

Therefore, recurrent oral ulceration is now an absolute criterion for the diagnosis of $\mathrm{BD}$, requiring, in addition, 2 criteria selected from genital ulceration, ocular inflammation, certain skin lesions and the pathergy test to make a definite diagnosis. A positive pathergy test is the development of cutaneous nodular pustules at a site of trauma, after approximately 24 hours. A needle stab site from venepuncturing would qualify as an appropriate site to inspect for such pustules, but it must be noted that this test can vary considerably between geographical areas.

Although clinical features such as arthritis and cutaneous manifestations are compatible with an immune complex mediated process the overall disease pattern cannot be entirely explained on such a basis. It is not, therefore, surprising that characteristic serological abnormalities are absent in BD. Patients with active disease may generate an acute phase response leading to a raised erythrocyte sedimentation rate (ESR), increased serum levels of C-reactive protein (CRP) and elevated plasma complement components such as $\mathrm{C} 3, \mathrm{C4}$, C9 and Factor B. ${ }^{7-9}$ The ESR, CRP and C9 seem to reflect the disease activity in some patients, but $\mathrm{C} 9$ is not available as a routine test in most laboratories. Polyclonal increases in serum $\operatorname{IgA}$ associated with certain clinical subtypes such as ocular, arthritic and neurological, have been reported ${ }^{10}$ but results from studies of immune complexes, both circulating and in tissues, have not demonstrated consistent changes. Reduced fibrinolytic activity is seen in BD and is usually due to decreased production of tissue plasminogen activator; however, this appears to be unrelated to the tendency to develop thromboses. ${ }^{11}$

The cellular infiltrate in the mucous membrane 
lesions (oro-genital ulcers) of $\mathrm{BD}$ is predominantly lymphocytes and monocytes, infiltrating both the dermis and epidermis and around the small blood vessels. Interestingly, as the lesion ages, so the neutrophil infiltrate increases. ${ }^{12}$ The cutaneous lesions can be divided into 2 types, those resembling erythema nodosum (EN) and those starting as sterile vesicles/pustules which evolve into deep punched out ulcers. Histology of the EN lesions reveals a small vessel vasculitis involving particularly the venules with a perivascular lymphocytic and mononuclear cellular infiltration and fibrin deposition in the vessel wall, whereas in contrast the punched out ulcers are characterized by a leucocytoclastic vasculitis (neutrophil infiltrate) with fibrinoid necrosis. ${ }^{13}$

Studies of peripheral blood $\mathrm{T}$ cells in BD have often given conflicting findings but this may be related to differences in patient populations, laboratory techniques, disease activity and therapy. Using a fluorescence cell scanner (FACScan), we have recently confirmed previous reports of a decrease in total peripheral blood $\mathrm{T}$ cells $(\mathrm{CD} 3+)^{14}$ and this resulted primarily from a reduction in the CD4 + population ( $T$ helper/inducer). In addition we demonstrated an overall increase in the proportion of activated (HLA-DR +) $T$ cells and it transpired that all the subsets of $T$ cells contributed to this, indicating marked cellular activation. In patients with active disease an increase in natural killer (NK) cells in peripheral blood is reported; however, their killing activity against K 562 target cells is reduced and this may be related to immature forms of NK cells being released into the circulation. ${ }^{15,16}$ Both in vitro and in vivo studies of neutrophils from patients with BD have demonstrated enhanced neutrophil migration, particularly with respect to the number of cells migrating; this effect was again most prominent in those with active disease. ${ }^{17}$

Although the aetiology of BD remains obscure, recent clinical observations suggest that exposure to streptococcal antigens may be a major provoking factor for disease activity in BD. Although cell-mediated immunity appears to be intact when judged by intradermal skin testing with PPD, Candida, and streptokinase - streptodornase antigens, ${ }^{18}$ an intense delayed type hypersensitivity (DTH) skin reaction is observed when other streptococcal antigens (streptococcal vaccines) are in- jected intradermally. ${ }^{19,20}$ A recent clinical report describes the onset of severe symptoms of BD shortly after dental treatment in two otherwise stable BD patients. ${ }^{21}$ The authors also cite the onset of similar symptoms in 4 patients who received streptococcal antigen skin tests. The authors argued that it was unlikely that the association was coincidental, or induced non-specifically by dental manipulation. They suggested that it was most likely that the flares of BD were induced by streptococcal related antigens used for skin tests, or released by certain microorganisms which entered the circulation from the oral cavity during the dental procedures. Kaneko et al..$^{20}$ had previously reported that patients with $\mathrm{BD}$ have chronically infected foci before the onset of diseases such as dental diseases and tonsillitis. They not only isolated streptococci from these infected foci but also demonstrated binding of a streptococcal group D antiserum to skin and mucosal lesional biopsies from patients with BD, particularly to blood vessels and at inflammatory foci. ${ }^{22}$

The possibility of viral rather than bacterial infections triggering BD must not be ignored and, in fact, a viral aetiology was suggested by Behçet in his original publication based on his observation of inclusion bodies in the ulcerations. ${ }^{1}$ Herpes simplex virus type 1 (HSV1) has long received attention as a likely candidate and HSV1 genome has been identified by hybridization in peripheral blood lymphocytes and monocytes of BD patients. ${ }^{23,24}$ cell responses to HSV1 show impaired ${ }^{3} \mathrm{H}$-thymidine uptake by CD4 + cells in BD when compared to seropositive HSV1 controls, indicating an impaired cellular response specific to HSV1. ${ }^{25}$

Major aberrations in the cellular immune system have therefore been demonstrated in BD and the intriguing possibility of $\mathrm{BD}$ being triggered by streptococcal antigens is being actively pursued. The multifactorial aetiology of this condition was recently exemplified by a study from Leeds entitled 'Is Behçet's disease triggered by childhood infection?' The group showed that an increased risk of BD was associated with tonsillectomy, a history of cold sores, large sibship size, late birth order, travel to countries with high incidence of disease and the first sexual intercourse before 16 years of age.$^{26}$ One is left to wonder what were the features with which there were no correlations!

\section{References}

1. Behçet, H. Uber rezidivierende, aphthose, durch ein Virus verursachte Geschwure am Mund, am Auge und an den Genitalien. Dermatol Wochenschir 1937, 36: 1152-1157.

2. Aoki, K., Fujioka, K., Katsumata, H. et al. Epidemiological studies on Behçet's disease in the Hokkaido district. Jpn $J$ Clin Ophthalmol 1971, 25: 2239-2248.

3. Chajek, T. \& Fainaru, M. Behçet's disease. Report of 41 cases and a review of the literature. Medicine 1975, 54: 179-196

4. Lehner, T., Batchelor, J.R., Challacombe, S.J. \& Kennedy, L. An immunogenetic basis for the tissue involvement in Behçet's syndrome. Immunology 1979, 37: 895. 
5. Yazici, H., Chamberlain, M.A., Schrender, I., D'Amaro, J. \& Muftuoglu, M. HLA antigens in Behçet's disease: a reappraisal by a comparative study of Turkish and British patients. Ann Rheum Dis 1980, 39: 344-348.

6. International Study Group for Behcet's Disease. Criteria for diagnosis of Behçet's disease. Lancet 1990, 335: 1078-1080.

7. Oshima, Y., Shimizu, T., Yokohari, R. et al. Clinical studies on Behçet's syndrome. Ann Rheum Dis 1963, 22: 36-45.

8. Adinolfi, M., Beck, S.E. \& Lehner, T. Serum levels of acute phase proteins, C9, factor B and lysozyme in Behcet's syndrome and recurrent oral ulcers. In: Lehner, T. and Barnes, C.G. (eds) Behçet's Syndrome: Clinical and Immunological Features. Academic Press, London, 1979, pp. 107-139.

9. Rumfeld, W.R., Morgan, B.P. \& Campbell, A.K. The ninth complement component in rheumatoid arthritis, Behcet's disease and other rheumatic diseases. Br J Rheumatol 1986, 25: $266-270$.

10. Scully, C.M., Lehner, T. \& Harfitt, R. Serum, salivary and lacrimal immunoglobulins in Behçet's syndrome and recurrent oral ulcers. In: Lehner, T. and Barnes, C.G. (eds) Behçet's Syndrome: Clinical and Immunological Features. Academic Press, London, 1979, pp. 77-89.

11. Aitchison, R., Chu, P., Cater, D.R., Harris, R.J. \& Powell, R.J. Defective fibrinolysis in Behçet's syndrome: significance and possible mechanisms. Ann Rheum Dis 1989, 48: 590-593.

12. Muller, W. \& Lehner, T. Quantitative electron microscopical analysis of leukocyte infiltration in oral ulcers in Behçet's syndrome. Br J Dermatol 1982, 106: 535-544.

13. Lakhanpal, S., Desmond O'Duffy, J. \& Lie, J.T. Pathology. In: Plotkin, G.R., Calabro, J.J., Desmond O'Duffy, J. (eds). Behçet's Disease: A Contemporary Synopsis. Futura Publishing Co., Mount Kisco, N.Y., 1988, pp. 102-142.

14. Ahmed, A.R. Lymphocyte studies in Behcet's syndrome. Dermatologica 1982, 164: 175-180.

15. Kaneko, F., Takahashi, Y., Muramatsu, R. et al. Natural killer cell numbers and function in peripheral lymphoid cells in Behçet's disease. Br J Dermatol 1985, 113: 313-318.

16. Hamzaoui, K., Ayed, K.H., Hamza, M. \& Touraine, J.L. Natural killer cells in Behçet's disease. Clin Exp Immunol 1988, 71: 126-131.
17. Efthimiou, J., Addison, I.E. \& Johnson, B.V. In vivo leucocyte migration in Behçet's syndrome. Ann Rheum Dis 1989, 48: 206-210.

18. Lehner, T. Immuno-pathology of Behçet's syndrome. In: Lehner, T. \& Barnes, C.G. (eds). Behçet's Syndrome: Clinical and Immunological Features. Academic Press, London, 1979, pp. 127-139.

19. Graykowsi, E.A., Barile, M.F., Lee, W.B. \& Stanley, H.R. Jr. Recurrent apthous stomatitis: clinical, therapeutic, histopathologic and hypersensitivity aspects. JAMA 1966, 196: 637-644.

20. Kaneko, F., Kaneda, T., Ohnishi, O. et al. Behçet's syndrome and infection allergy. (1) Detection of chronic infectious foci and immune responses to bacterial vaccines in vivo and in vitro. Jpn J Allergol 1978, 27: 440-447.

21. Mizushima, Y., Matsuda, T., Hoshi, K. \& Ohno, S. Induction of Behçet's disease symptoms after dental treatment and streptococcal antigen skin test. $J$ Rheumatol 1988, 15: 1029-1030.

22. Kaneko, F., Takahashi, Y., Muramatsu, Y. \& Miura, Y. Immunological studies on aphthous ulcer and erythema nodosum-like eruptions in Behçet's disease. $\mathrm{Br} J$ Dermatol 1985, 113: 303-312.

23. Eglin, R.P., Lehner, T. \& Subak-Sharpe, J.H. Detection of RNA complementary herpes-simplex virus in mononuclear cells from patients with Behçet's syndrome and recurrent oral ulceration. Lancet 1982, ii: 1356-1360.

24. Bonass, W.A., Bird-Steward, J.A., Chamberlain, M.A. \& Halliburton, I.W. Molecular studies in Behçet's syndrome. In: Lehner, T. \& Barnes, C.G. (eds). Recent Advances in Behçet's Disease. Royal Society of Medicine Services, London, 1986, pp. 37-41.

25. Young, C., Lehner, T. \& Barnes, G.C. CD4 and CD8 cell responses to herpes simplex virus in Behçet's disease. Clin Exp Immunol 1988, 73: 6-10.

26. Cooper, C., Pippard, E.C., Sharp, H., Wickham, C., Chamberlain, M.A. \& Barker, J.P. Is Behçet's disease triggered by childhoold infection? Ann Rheum Dis 1989, 48: 421-423. 